\title{
Molecular cloning and characterization of the $S 6 K-p 70$ gene in Chinese honeybees, Apis cerana cerana (Hymenoptera: Apidae)
}

\author{
YINGQI $\mathrm{CAI}^{1}$, TAOBO $\mathrm{AI}^{1}, \mathrm{XIAOLI}^{\mathrm{Y}} \mathrm{YU}^{1}$, BaOHUA $\mathrm{XU}^{2 *}$ and XINGQI GUO ${ }^{1 *}$ \\ ${ }^{1}$ College of Life Sciences and ${ }^{2}$ College of Animal Science and Technology, Shandong Agricultural University, Taian, \\ Shandong, 271018, P. R. China; e-mails: caiyingq@sdau.edu.cn (Y. Cai), crazywolf119.-@163.com (T. Ai), \\ dos-888@163.com (X.Yu),bhxu@sdau.edu.cn (B.Xu), and xqguo@sdau.edu.cn (X. Guo)
}

Key words. Apidae, ribosomal protein S6 kinase, Apis cerana cerana, development, environmental stresses, expression pattern

\begin{abstract}
The ribosomal protein S6 kinase (S6K) plays a pivotal role in developmental processes and cell survival by participating in protein synthesis relevant signaling pathways. In the present study, an $S 6 K$ gene (AccS6K-p 70 ) was isolated and characterized from the Chinese honeybee, Apis cerana cerana (Fabricius) (Hymenoptera: Apidae), an important economic insect in the agricultural industry. The cDNA of $A c c S 6 K-p 70$ was $1683 \mathrm{bp}$ in length and predicted to encode a protein of 467 amino acid residues. Sequence and structure analysis showed that there was a conserved catalytic domain in AccS6K-p70, whilst a phosphorylation site was found in the conserved part of the catalytic domain. Development relevant transcription factor binding sites found in the 5'flanking region of $A c c S 6 K-p 70$ suggest that $A c c S 6 K-p 70$ might be involved in $A$. c. cerana development. Furthermore, quantitative PCR revealed that the expression levels of $A c c S 6 K-p 70$ were higher in head and thorax than in other tissues. The $A c c S 6 K-p 70$ was highly expressed in both larvae and adults compared with that in pupae, whilst expression of the gene was significantly downregulated by hydrogen peroxide $\left(\mathrm{H}_{2} \mathrm{O}_{2}\right)$ (although initially and slightly increased by it) and pyriproxyfen (a juvenile hormone analogue insecticide) stresses. These results suggest that AccS6K-p70 may play critical roles in developmental processes and cell survival in A. c. cerana, whilst both oxidative stress and pyriproxyfen may impair S6K-p70 mediated developmental processes by down-regulation of $A c c S 6 K-p 70$ expression.
\end{abstract}

\section{INTRODUCTION}

Regulation of protein synthesis is highly relevant to the development of individual organisms by influencing cell growth and proliferation relevant signal transduction (Ferrari \& Thomas, 1994). Ribosomal RNA (rRNA) protein components greatly influence the protein synthesis at the level of initiation through a complex set of processes. The 40S ribosomal subunit of the ribosome is one of such translational components. Protein S6, an important component of the 40S ribosomal subunit, performing its biological functions through phosphorylation via ribosomal protein S6 kinase (S6K).

There are two common isoforms of S6K, S6K-p70 and S6K-p85, which are encoded by two distinct mRNA transcripts generated from a single gene (Reinhard et al., 1992). The isoform S6K-p85 possesses an additional 23amino acid extension at its $\mathrm{N}$ terminus, which contains a nuclear localization signal constitutively targeting this isoform to the nucleus, whereas S6K-p70 seems to be located in the cytoplasm (Reinhard et al., 1994). Both of these isoforms are activated by mitogenic stimulation (Reinhard et al., 1992). However, studies indicate that S6K-p70 located in cytoplasm is involved in a wide range of signaling pathways in response to development and survival (Lane et al., 1993; Harada et al., 2001; Chiang \& Abraham, 2007).

According to recent studies, S6K-p70 controls development by regulating cell growth and proliferation. Insulin, a common growth factor, is thought to promote cell growth in both mammals and the fruitfly, Drosophila melanogaster (Meigen) by controlling protein synthesis through the activation of the phosphatidylinositol 3-kinase (PI3K) signaling pathway, which includes PI3K, phosphoinositide-dependent protein kinase 1 (PDK1), Akt, target of rapamycin (TOR) and S6K (Rintelen et al., 2001; Miron et al., 2003; Chiang \& Abraham, 2007). Additionally, inhibition of S6K-p70 phosphorylation by phosphatase and the tensin homologue (PTEN), extracellular signal-regulated kinase (ERK) and the immunosuppressant drug rapamycin could influence cell size and cognition in mammals (Krab et al., 2008; Scheper et al., 2008; Distefano et al., 2009). For cell proliferation, previous research indicates that $\mathrm{S} 6 \mathrm{~K}-\mathrm{p} 70$ is essential in serum-induced entry of cells into the $S$ phase (Lane et al., 1993). In addition to development, S6K-p70 also signals cell survival in mammals and insects. Research on S6K-p70 shows that S6K-p70, acting as a dual pathway kinase, also participates in cell survival by inactivating the pro-apoptotic molecule BAD (Harada et al., 2001). Other research suggested that S6K-p70 in mTOR pathway possesses anti-apoptotic functions in insect cells (Foster, 2004). Recently, S6K-p70 was found to be involved in honeybee, Apis mellifera L. royalactininduced caste development. It was suggested that the expression level of S6K-p70 gene plays a role in the diphenic differentiation process of honeybee larvae,

\footnotetext{
* Corresponding authors.
} 
which determined the phenotype of queens or workers (Azevedo et al., 2011). During this process, up-regulation of S6K-p70 gene expression levels correlate with increased body size and decreased development time (Kamakura, 2011).

The Chinese honeybee, Apis cerana cerana (Fabricius) (Hymenoptera: Apidae), like A. mellifera in other parts of the world, is as a major plants pollinator in China and thus plays an essential role in the agricultural industry and the ecosystem generally. Because of the complex processes associated with its development, A. c. cerana, is consequently known to suffer (as with other bee species elsewhere), from increasingly severe environmental stresses due to the rapidly expanding industrial and economic potential of the country, including agricultural with all this means in terms of pollution and pesticide usage (Xu et al., 2009). Therefore, study on $S 6 K-p 70$ in A. c. cerana is of considerable importance. In this study, the $S 6 K$ gene $A c c S 6 K-p 70$ in A. c. cerana was isolated and characterized for the first time. The expression in terms of mRNA levels and development related transcription factor binding sites found in $A c c S 6 K$ - $p 70$ 5'-flanking region suggest that $A c c S 6 K-p 70$ may be involved in multiple developmental processes (molting, movement relevant muscle and organ development, learning and memory formation) and cell survival in resistance to oxidative stress during the insect's life span. In addition, both the juvenile hormone analogue pyriproxyfen (a pyridine-based insecticide) and oxidative stress may impair development of the bee larva through downregulation of $A c c S 6 K-p 70$ expression.

\section{MATERIAL AND METHODS}

\section{Biological specimens and treatments}

The Chinese honeybee, $A$. $c$. cerana used in this experiment was maintained at the experimental apiary of Shandong Agricultural University in Taian, China. Worker bees were collected at emergence from combs in outdoor beehives. The larvae, pupae and adult bees were classified according to the age and shape. Fifth larval instars (L5), brown ( $\mathrm{Pb}$ ) eyes pupae and fiveday-old workers were collected for AccS6K-p70 expression analysis in different development stages. Tissues from the head, thorax, and abdomen were isolated from the brown $(\mathrm{Pb})$ eyes pupae to detect $A c c S 6 K-p 70$ expression profile in different tissues. For pesticide and hydrogen peroxide $\left(\mathrm{H}_{2} \mathrm{O}_{2}\right)$ treatments, 5-day-old worker bees were caged in three groups $(\mathrm{n}=$ 40 /group) at a constant temperature $\left(33^{\circ} \mathrm{C}\right)$ and humidity $(80 \%)$ and fed a pollen-and-sucrose solution for two days before treatments. Pyriproxyfen and $\mathrm{H}_{2} \mathrm{O}_{2}$ were diluted to a final concentration of $20 \mathrm{mg} / \mathrm{l}$ and $2 \mathrm{mM}$ in distilled water, respectively, and $0.5 \mu 1$ was injected to the thoracic notum of worker honeybees in groups 1 and 2. The adult worker bees in the control group (group 3) were treated with distilled water. All of the bees were thereafter harvested at the appropriate time and stored deep frozen at $-80^{\circ} \mathrm{C}$.

\section{Primers}

The primers used in this experiment are listed in Table 1.

\section{RNA extraction, cDNA synthesis, and DNA isolation}

Total RNA was extracted using Trizol reagent (Invitrogen, Carlsbad, CA, USA) in accordance with the manufacturer's protocol. Total RNA was digested with RNase-free DNase-I to remove the genomic DNA. The first-strand cDNA was obtained by the EasyScript First-Strand cDNA Synthesis SuperMix (TransGen Biotech, Beijing, China) according to the manufacturer's protocol. Similarly, genomic DNA was isolated using the EasyPure Genomic DNA Extraction Kit according to the manufacturer's protocol (TransGen Biotech).

\section{The full-length cDNA isolation of AccS6K-p 70}

Based on the conserved region of the $S 6 K-p 70$ genes of three organisms, the wasp parasitoid, Nasonia vitripennis (Ashmead) (Hymenoptera: Pteromalidae), the filarial nematode Brugia malayi Brug (Spirurida: Onchocercidae) and Apis mellifera, degenerate primers MF and MR were designed and synthesized for the amplification of the middle region of AccS6K-p70. PCR conditions were as follows: $94^{\circ} \mathrm{C}$ (denaturation) for $5 \mathrm{~min}$, followed by 35 cycles of $94^{\circ} \mathrm{C} / 40 \mathrm{~s}, 51^{\circ} \mathrm{C} / 40 \mathrm{~s}$ (annealing), $72^{\circ} \mathrm{C} / 60 \mathrm{~s}$ (extension), with a final extension at $72^{\circ} \mathrm{C}$ for $10 \mathrm{~min}$ using EasyTaq DNA polymerase (TransGen Biotech). The PCR product were purified, cloned into the pMD18-T vector (TaKaRa, Dalian, China) and sequenced.

Based on the internal conservative fragment obtained, four specific primers $(5 \mathrm{O}, 5 \mathrm{~N}, 3 \mathrm{O}, 3 \mathrm{~N})$ were designed on the internal fragment. For 5' rapid amplification of cDNA ends (RACE), the first-strand cDNA was purified by the Wizard DNA Clean-up System (Promega, Madison, WI, USA), and then the poly-C tail was added at the 5' end of the purified cDNA with dCTP and terminal deoxynucleotidyl transferase (TaKaRa). With the poly-C added cDNA as templates, the primary round was performed using $5 \mathrm{O}$ and an Abridged Anchor Primer (AAP) as primers. The products of the primary round of PCR were diluted and used as the templates of the nested PCR. 5N and Abridged Universal Amplification Primer (AUAP) were used as primers for this round. The conditions for the two rounds of PCR were as below: $94^{\circ} \mathrm{C}$ for $5 \mathrm{~min}$, followed by 35 cycles of $94^{\circ} \mathrm{C} / 40 \mathrm{~s}$, $51^{\circ} \mathrm{C} / 40 \mathrm{~s}, 72^{\circ} \mathrm{C} / 60 \mathrm{~s}$, and a final extension at $72^{\circ} \mathrm{C}$ for $10 \mathrm{~min}$. The nested PCR products were purified and cloned into pMD18-T vectors (TaKaRa) for sequencing.

For 3' RACE, primer $3 \mathrm{O}$ and the universal primer $\mathrm{B} 26$ were used for the first round PCR. With the diluted products of the primary PCR as templates, the nested PCR was performed using the $3 \mathrm{~N}$ and the $\mathrm{B} 25$ as primers. The conditions of the two rounds of PCR were performed as following: $94^{\circ} \mathrm{C}$ for $5 \mathrm{~min}$, followed by 35 cycles of $94^{\circ} \mathrm{C} / 40 \mathrm{~s}, 55^{\circ} \mathrm{C} / 40 \mathrm{~s}, 72^{\circ} \mathrm{C} / 40 \mathrm{~s}$, and a final extension at $72^{\circ} \mathrm{C}$ for $10 \mathrm{~min}$. The nested PCR products were purified and cloned into pMD18-T vectors (TaKaRa) for sequencing.

According to the sequence obtained separately, two specific primers were designed (RSK-F, RSK-R) for the full-length cDNA amplification. PCR conditions were as follows: $94^{\circ} \mathrm{C}$ for $5 \mathrm{~min}$, followed by 35 cycles of $94^{\circ} \mathrm{C} / 40 \mathrm{~s}, 50^{\circ} \mathrm{C} / 40 \mathrm{~s}, 72^{\circ} \mathrm{C} / 90$ $\mathrm{s}$, and a final extension at $72^{\circ} \mathrm{C}$ for $10 \mathrm{~min}$. The PCR products were purified and cloned into pMD18-T vectors for sequencing (TaKaRa).

\section{Amplification of genomic sequence and the 5'-flanking region of $A c c S 6 K-p 70$}

In order to obtain the genomic sequence of $A c c S 6 K-p 70$, three pairs of primers (GF1, GR1, GF2, GR2, GF3, GR3) were designed according to the full-length cDNA of AccS6K-p70 and the genomic sequence of $A m S 6 K-p 70$. With the DNA extracted from A. c. cerana as templates, three fragments of the $A c c S 6 K-p 70$ genomic DNA were obtained and spliced to form the full-length genomic DNA. The program of PCR was performed as follows: $94^{\circ} \mathrm{C}$ for $5 \mathrm{~min}$, followed by 35 cycles of $94^{\circ} \mathrm{C} / 40 \mathrm{~s}, 50^{\circ} \mathrm{C} / 40 \mathrm{~s}, 72^{\circ} \mathrm{C} / 90 \mathrm{~s}$, and a final extension at $72^{\circ} \mathrm{C}$ for $10 \mathrm{~min}$. 
TABLE. 1. The primers used in this experiment.

\begin{tabular}{|c|c|c|}
\hline Abbreviation & Sequence (5'-3') & Description \\
\hline MF & GAMRGAGTWCARYTATCAGAG & Degenerate primer, forward \\
\hline MR & $\begin{array}{l}\text { CKTCBARWACACTDGGBGCWAC } \\
(\mathrm{R}=\mathrm{A}, \mathrm{G} ; \mathrm{V}=\mathrm{G}, \mathrm{A}, \mathrm{C} ; \mathrm{N}=\mathrm{A}, \mathrm{T}, \mathrm{G}, \mathrm{C} ; \mathrm{H}=\mathrm{A}, \mathrm{T}, \mathrm{C})\end{array}$ & Degenerate primer, reverse \\
\hline 50 & СТTTTCСАТАТССАССТTСТССАА & 5' RACE reverse primer, outer \\
\hline $5 \mathrm{~N}$ & CATAATTCAAAATCTTGCGGACCAG & 5' RACE reverse primer, nested \\
\hline AAP & GGCCACGCGTCGACTAGTAC (G) 14 & Abridged Anchor Primer, outer \\
\hline AUAP & GGCCACGCGTCGACTAGTAC & Abridged Universal Amplification Primer, nested \\
\hline 30 & CGATGAACAATTCACAGCAACTGTACC & 3' RACE reverse primer, outer \\
\hline $3 \mathrm{~N}$ & GTACCAGTTGATTCACCAGTTGAAAGTAC & 3' RACE reverse primer, nested \\
\hline B26 & $\operatorname{GACTCTAGACGACATCGA~}(T)_{18}$ & Universal primer, outer \\
\hline $\mathrm{B} 25$ & GACTCTAGACGACATCGA & Universal primer, nested \\
\hline RSK-F & ACAAAATAGTAAATAATCTTCG & Full-length cDNA primer, forward \\
\hline RSK-R & TTAGAAATTAAAAAGCGGACC & Full-length cDNA primer, reverse \\
\hline GF1 & ACAAAATAGTAAATAATCTTCG & Genomic sequence primer, forward \\
\hline GR1 & TGTGAAGAGTTCTCCTCCAC & Genomic sequence primer, reverse \\
\hline GF2 & GCATTTTCTTAGAAGATACTGCTTG & Genomic sequence primer, forward \\
\hline GR2 & ATCCTAATCTTTGTGCTACTTGTCT & Genomic sequence primer, reverse \\
\hline GF3 & TGGTGGAGTTTAGGTGC & Genomic sequence primer, forward \\
\hline GR3 & TTAGAAATTAAAGCGGACCTATATC & Genomic sequence primer, reverse \\
\hline PF1 & CCGCATTTACGCACATACGT & Promoter sequence primer, forward \\
\hline PR1 & АСTTCCTCTTATTTGCGTGTTC & Promoter sequence primer, reverse \\
\hline PF2 & CGAACACATTAAGATCAATTAAAG & Promoter sequence primer, forward \\
\hline PR2 & GTGATAGATTAAATTACCTATAAACGT & Promoter sequence primer, reverse \\
\hline PF3 & TTGGATTGAAGACTGATTTAT & Promoter sequence primer, forward \\
\hline PR3 & GATGCTCCTCTTTGTAACCT & Promoter sequence primer, reverse \\
\hline PF4 & GTAGAGTCAACTTATTTCAC & Promoter sequence primer, forward \\
\hline PR4 & TCGTAGATGGCGTAATCATAATC & Promoter sequence primer, reverse \\
\hline FLF & TCAAGACGAGTCGGATGATGAT & Quantitative PCR primer, forward \\
\hline FLR & СТTTTССАТАТССАССТTСТСС & Quantitative PCR primer, reverse \\
\hline$\beta-\mathrm{s}$ & GTTTTCCCATCTATCGTCGG & Standard control primer, forward \\
\hline$\beta-\mathrm{x}$ & TTTTCTCCATATCATCCCAG & Standard control primer, reverse \\
\hline
\end{tabular}

To obtain the 5'-flanking region of $A c c S 6 K-p 70$, inversionpolymerase chain reaction (I-PCR) was performed. The total DNA extracted from A. c. cerana was digested by restriction endonucleases $\operatorname{DraI}$ and $N$ si I (TaKaRa), respectively, and then the digested products were ligated with $\mathrm{T}_{4}$ DNA ligase (TaKaRa). Forward primers (PF1 and PF2) and reverse primers (PR1 and PR2) were designed according to the genomic sequence of $A c c S 6 K-p 70$. For the first round of PCR, the DraI digested and ligated products were used as templates and PF1 and PR1 were used as primers. With the first round products as templates, the nested PCR was performed using primers PF2 and PR2. The two rounds of PCR were performed as follows: $94^{\circ} \mathrm{C}$ for $5 \mathrm{~min}$, followed by 35 cycles of $94^{\circ} \mathrm{C} / 40 \mathrm{~s}, 50^{\circ} \mathrm{C} / 40 \mathrm{~s}$, $72^{\circ} \mathrm{C} / 60 \mathrm{~s}$, and a final extension at $72^{\circ} \mathrm{C}$ for $10 \mathrm{~min}$. According to the sequencing results, forward primers (PF3 and PF4) and reverse primers (PR3 and PR4) were designed based on 5'flanking region. After two rounds of PCR, another fragment of the 5'-flanking region was obtained. According to the two fragments obtained as described above, primers PF5 and PR5 were designed and used to validate the 5'-flanking region amplified separately by I-PCR.

\section{Bioinformatic analysis and phylogenetic tree construction}

Homologous sequences of $S 6 K-p 70$ were collected from the bioinformatics tools available at the NCBI server (http://blast.ncbi.nlm.nih.gov/Blast.cgi). Multiple alignment of the sequences of S6K-p70 proteins was performed using the DNAman software 5.2.2. The primers were designed with DNAclub and DNAman software. Phylogenetic analysis of the putative amino acid sequences of S6K-p70 proteins in different species was conducted using the molecular evolution genetics analysis (MEGA) software. Secondary structure was analyzed by online secondary structure prediction software SOPMA (http://npsa-pbil.ibcp.fr/cgi-bin/npsa_automat.pl?page=/NPSA/n psa_seccons.html) (Geourjon \& Deleage, 1995). Threedimentional (3D) protein structures were constructed using an online protein 3D structure prediction tool, SWISS-MODEL (http://swissmodel.expasy.org/).

\section{Fluorescence real-time quantitative PCR}

The $\beta$-actin gene was used as the internal control of the quantitative PCR. The $\beta$-actin gene primers were designed according to $\mathrm{Yu}$ et al. (Yu et al., 2011). Specific quantitative PCR primers (FQ1 and FQ2) were designed based on the $A c c S 6 K-p 70$ cDNA sequence obtained above. We have firstly validated the primers 


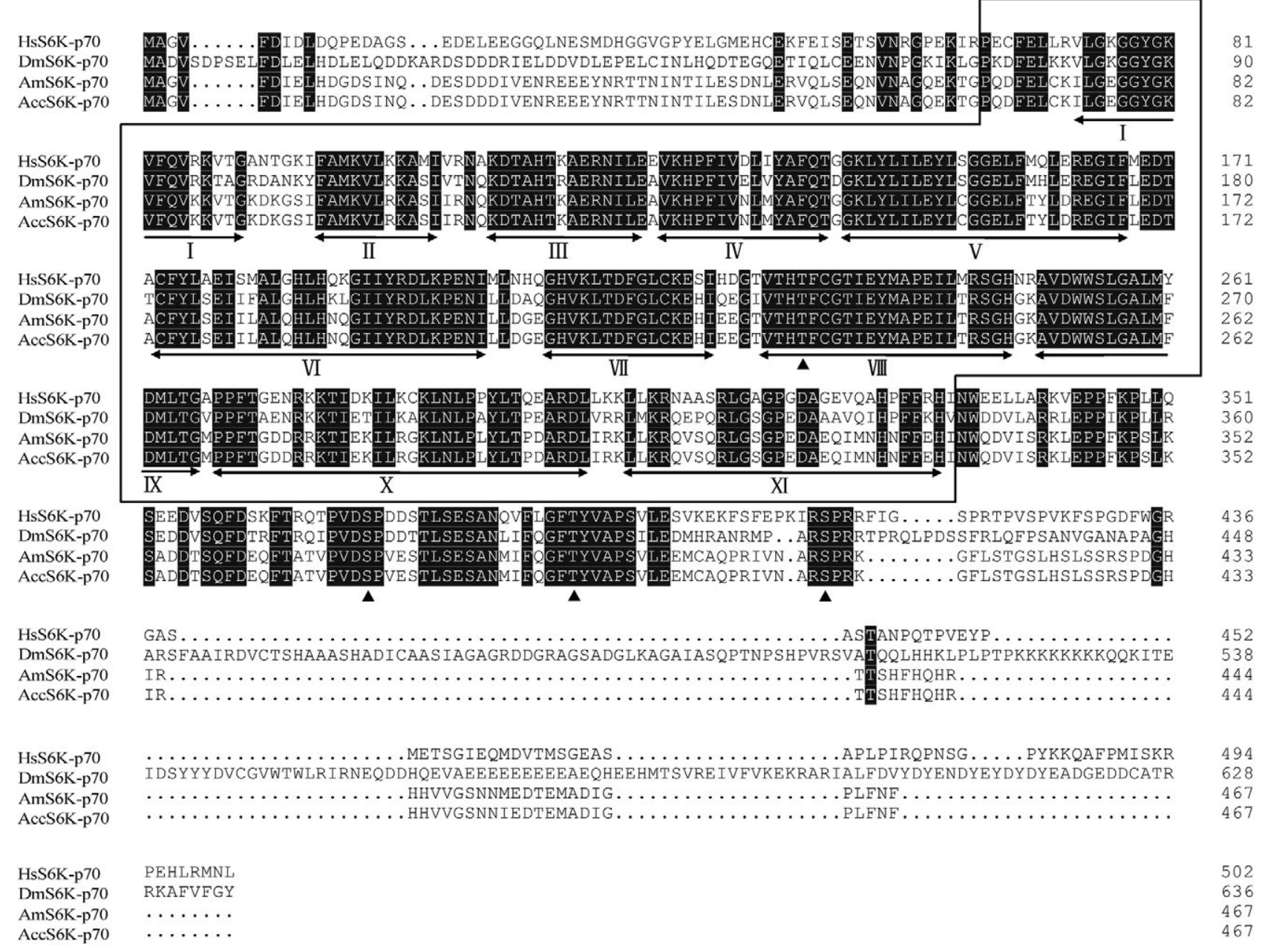

Fig. 1. Sequence analysis and homologous alignment of AccS6K-p70 and other S6K-p70s. The sequences of the proteins used in the alignment are DmS6K-p70 (AAC47429), HsS6K-p70 (AAA36411), AmS6K-p70 (XP624928), and AccS6K-p70 (FJ966885). The alignment is created by the software DNAman. The dark regions represent the conserved parts of the sequences of the four proteins. The conserved catalytic domain in S6K-p70 proteins is boxed and subdomains are indicated with Roman numerals. The conserved phosphorylation sites are marked by arrowheads $(\mathbf{\Lambda})$.

of these two genes. The efficiency of $\beta$-actin and AccS6K-p 70 both approached $100 \%$. The melting curves had single peaks and the correlation coefficients $\left(\mathrm{R}^{2}\right)$ were 0.999 and 0.998 , respectively. Quantitative PCR was performed using SYBR PrimeScript RT-PCR Kit (TaKaRa) on CFX96 ${ }^{\mathrm{TM}}$ Real-time System (Bio-Rad, CA, USA) under the following thermal cycling program: $95^{\circ} \mathrm{C}$ for $30 \mathrm{~s}$, followed by 40 cycles of $95^{\circ} \mathrm{C} / 10 \mathrm{~s}, 53^{\circ} \mathrm{C} / 20 \mathrm{~s}, 72^{\circ} \mathrm{C} / 15 \mathrm{~s}$, and the melt cycle from $65^{\circ} \mathrm{C}$ to $95^{\circ} \mathrm{C}$. At least three individuals were prepared for each sample which was analyzed in triplicate. The amplification and standard curves were developed and analyzed by CFX Manager Software version 1.1. The $-\Delta \Delta \mathrm{C}_{\mathrm{T}}$ method (Livak \& Schmittgen, 2001) was used to verify the different transcript levels. The Statistical Analysis System (SAS) version 9.1 (SAS Institute, Inc. Cary, NC, USA) was employed to calculate the significant differences among samples.

\section{RESULTS}

\section{Cloning and characterization of the full-length CDNA of $\operatorname{AccS6K-p70}$}

Based on the sequence information of $S 6 K-p 70$ gene in $N$. vitripennis, $B$. malayi and $A$. mellifera, the full-length
cDNA of $A c c S 6 K-p 70$ was cloned using RT-PCR and RACE-PCR. The full-length cDNA (GenBank accession no. FJ966885) was 1683 bp in length with a 1404 bp open reading frame (ORF), a 235 bp 5' UTR and a 44 bp 3' UTR. The newly cloned gene was predicted to encode a protein of 467 amino acid residues with a putative molecular mass of $52.67 \mathrm{kDa}$ and an isoelectric point of 5.34 .

\section{Homologous alignment and sequence analysis of AccS6K-p70}

Protein sequence alignment indicated that AccS6K-p70 shared high homology (99.79\%) with AmS6K-p70, while the homology between AccS6K-p70 and DmS6K-p70 was $47.96 \%$, which was lower than that $(56.75 \%)$ between AccS6K-p70 and HsS6K-p70. It was shown that the similarity of S6K-p70 protein in A. c. cerana, A. mellifera, D. melanogaster and Homo sapiens was high in terms of catalytic domain but relatively low in the $\mathrm{N}$-terminal and C-terminal regions (Fig. 1). Moreover, several conserved domains, such as a catalytic domain, a 


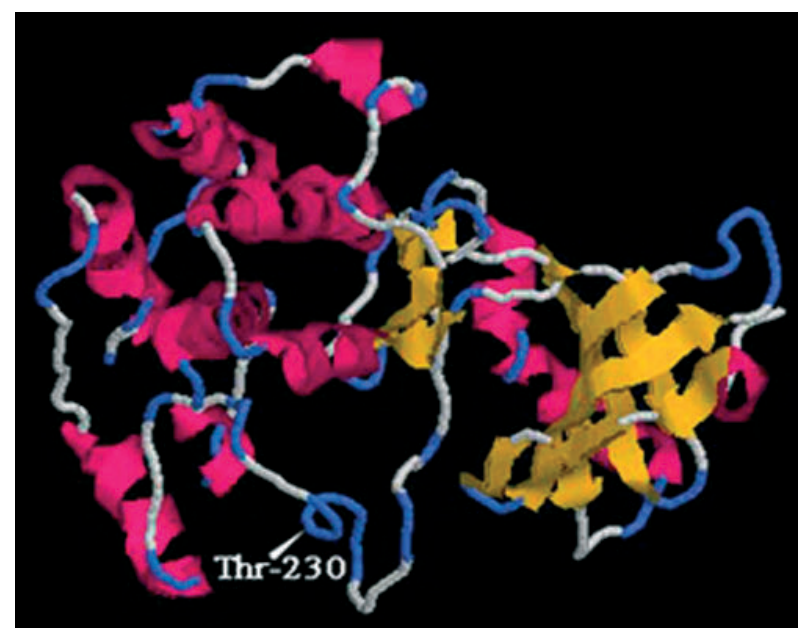

Fig. 2. The tertiary structure of AccS6K-p70. The location of the phosphorylation site Thr-230 is marked by arrowhead.

segment immediately carboxyl-terminal to the catalytic domain and an S6 kinase autoinhibitory pseudosubstrate (SKAIPS) domain, were identified in the AccS6K-p70 protein (Weng et al., 1998) (Fig. 1). In the catalytic domain, there were eleven subdomains and a Thr phosphorylated site found in the eighth subdomain (Watson et al., 1996; Stewart et al., 1996) (Fig. 1). Sequence characterization of the protein AccS6K indicated that this protein did not possess the additional N-terminus extension, which existed in S6K-p85 proteins.

\section{Protein structure analysis of AccS6K-p70}

To elucidate the structure characterization of AccS6Kp70, secondary and tertiary structure of AccS6K-p70 were predicted and analyzed. Secondary structure predicted by SOPMA revealed that the AccS6K-p70 protein comprises $28.48 \%$ alpha helix, $14.35 \%$ extended strands, and $57.17 \%$ random coiling. Furthermore, the tertiary structure of AccS6K-p70 was predicted using the 3D structure prediction tool, SWISS-MODEL (Guex \& Peitsch, 1997; Schwede et al., 2003; Arnold et al., 2006), and HmS6K-p70 (PDB code: 3a62A) was chosen as the template for homologous modeling of the AccS6K-p70 protein. The putative conserved phosphorylated amino acid residue was marked in the 3D image of AccS6K-p70 (Fig. 2). It was found that the Thr phosphorylated site in the catalytic domain was located in the conserved part of AccS6K-p70, which might play a critical role/s in the catalytic activity of AccS6K-p70.

\section{Phylogenetic analysis at the protein level}

In order to investigate the evolutionary relationship of S6K-p70 in different species, a phylogenetic tree was constructed and analyzed (Fig. 3). This revealed that the S6K-p70 proteins could be classified into three broad groups - Mammalia, Aves and Insecta. Compared with the relationship between S6K-p70 proteins in Mammalia and Aves, the difference between S6K-p70 proteins in Insecta was relatively significant. The $\mathrm{S} 6 \mathrm{~K}-\mathrm{p} 70$ in $A$. $c$. cerana was affiliated with AmS6K-p70 derived from $A$. mellifera, and the S6K-p70 protein from Hymenoptera

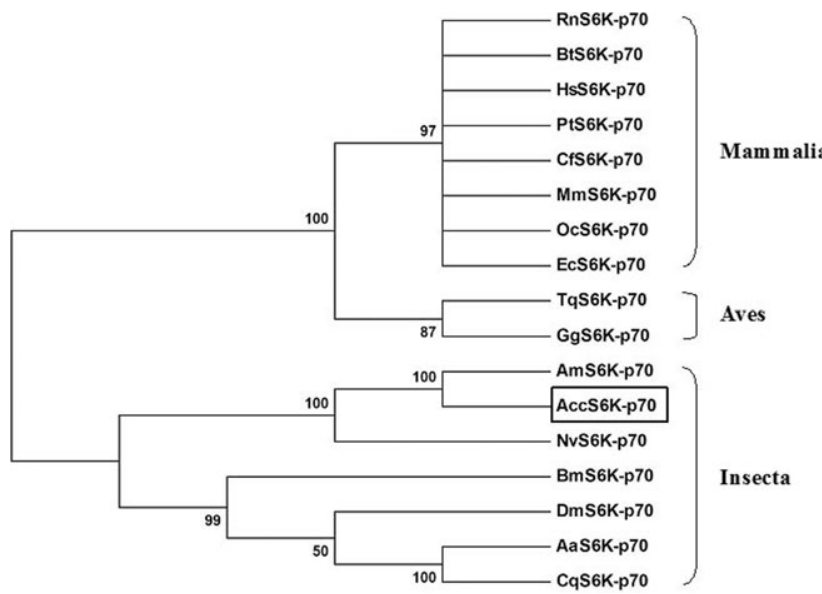

Fig. 3. Phylogenetic analysis of S6K-p70 from different species. The phylogenetic tree is generated by MEGA. The amino acid sequences of the S6K-p70 proteins used for construction of the phylogenetic tree are all deposited in the GenBank database under the following accession numbers: RnS6K-p70 (AAA42103), BtS6K-p70 (NP991385), $\quad$ HsS6K-p70

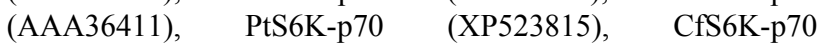
(XP537702), MmS6K-p70 (NP001107806), OcS6K-p70 (NP001095160), EcS6K-p70 (XP001503803), TqS6K-p70 (XP002199168), GgS6K-p70 (NP001025892), AmS6K-p70 (XP624928), AccS6K-p70 (FJ966885), NvS6K-p70 (XP001600462), BmS6K-p70 (NP001124378), DmS6K-p70 (AAC47429), AaS6K-p70 (XP001650653), and CqS6K-p70 (XP001844450).

was obviously different from that in Diptera and Lepidoptera. These results show that AccS6K-p70 might have evolved specifically during the ancient divergence of insect orders (Grimaldi \& Engel, 2005).

\section{Isolation and structural analysis of the full-length DNA of AccS6K-p 70}

To better understand the $A c c S 6 K-p 70$ gene in DNA level, the genomic DNA of $A c c S 6 K-p 70$ was isolated (GenBank accession no. JF915528). Sequence analysis

TABLE. 2. The length and GC content of all exons and introns of $A c c S 6 K-p 70$.

\begin{tabular}{cccccc}
\hline Exon & $\begin{array}{c}\text { Length } \\
(\mathrm{bp})\end{array}$ & $\begin{array}{c}\text { GC con- } \\
\text { tent }(\%)\end{array}$ & Intron & $\begin{array}{c}\text { Length } \\
(\mathrm{bp})\end{array}$ & $\begin{array}{c}\text { GC con- } \\
\text { tent }(\%)\end{array}$ \\
\hline 1 & 87 & 35.63 & 1 & 72 & 18.06 \\
2 & 41 & 19.51 & 2 & 213 & 11.74 \\
3 & 175 & 32 & 3 & 57 & 15.79 \\
4 & 84 & 32.14 & 4 & 75 & 13.33 \\
5 & 134 & 29.1 & 5 & 155 & 9.68 \\
6 & 63 & 28.57 & 6 & 67 & 16.42 \\
7 & 129 & 30.23 & 7 & 113 & 12.39 \\
8 & 91 & 40.66 & 8 & 83 & 14.46 \\
9 & 117 & 29.91 & 9 & 121 & 11.57 \\
10 & 132 & 34.09 & 10 & 72 & 12.5 \\
11 & 108 & 33.33 & 11 & 154 & 9.74 \\
12 & 170 & 41.76 & 12 & 115 & 14.78 \\
13 & 73 & 35.62 & & & \\
\hline
\end{tabular}




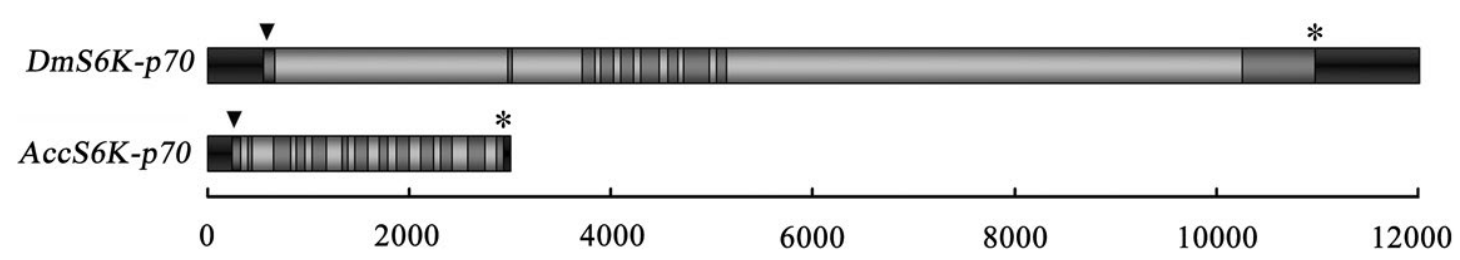

Fig. 4. Schematic representation of the genomic structure of DmS6K-p70 and $A c c S 6 K-p 70$. The figure is generated using Excel software, and the length of the genomic sequences is drawn according to the scale below. The 5'-UTR and 3'-UTR are highlighted with black bars, and the introns and exons are represented by light and dark gray bars, respectively. The initiation and termination codons are represented by arrowheads $(\mathbf{v})$ and asterisks $(*)$, respectively.

showed that the genomic DNA of AccS6K-p70 was 2998 bp in length and consisted of 13 exons and 12 introns. The GC content $(\%)$ of all the 13 exons ranged from 19.5 to 41.8 , while the GC content $(\%)$ of all the 12 introns was relatively low, ranging from 9.7 to 18.1 (Table 2). The introns all showed a high AT content and harboured the conserved GT and AG dinucleotides at the 5' and 3' splice sites (Table 2). As homologous alignment revealed that homology between AccS6K-p70 and DmS6K-p70 was relatively low, to analyze sequence similarity in DNA level, the genomic structure of AccS6K-p70 and $D m S 6 K-p 70$ was compared (Fig. 4). The structure comparison indicates that the genomic DNA of AccS6K-p70 and $D m S 6 K-p 70$ are different, both in number and length of introns. There were 10 exons and 9 introns in the DmS6K-p70 genomic DNA, and the first and the ninth introns are extremely long in comparison to the introns in AccS6K-p70 genomic DNA (Fig. 4).

$$
\text { ATGCATATTAAAATGATGAAGTATCGTCTATGT ATATATATA GTTAT GAATTTGATAAATAAAAGT }
$$

ATTCATCAATTAATTTATACTTTTCTTATCTTTTTATTTTAATTTAATATGTATTCATATAAAATGTATTACTTAAATAAA

TATTTCTATTATCTTCTATCAATATACCAAATATACTAATGTATCACATAACCTATAAATTATAAATTATTTAAATAAATG -1183

TTTCTAGTGATATATTAAAAAAATGGATATATTAAAAAAAATATTTTTAATAACATATCTTAACTAAAGTATAACTATATA -1102

AATTTGATTTATAGATACTGTTATAATTTGTAGATTAGTATAATTGTAAATAGTTTCATTAAAATCTTACATCAATTAAAC -1021

GTTTTATAAAATTTTACATTTCCATTGCAATAAATATGTCTTTATGATTTCAATTTACTTACAATTGTTAATTAATTTAAA -940

DRIF

DCF2

ATAATTAATTAGTTTGAATAATCGACAAAAATATGAAATATTTCAGTCATCTAATACGAATAAATAGCAA ATATATACAAT

DRIF

GATTAATTGTAATCAATTCAATATAATATCGTAAATAGATTTCGTTGTATTGTACAAAATATTAAATAATTAAAATTTTAA

TTATTTTTTTCTTTTCTATTTGATATAATTATACAAAATTTAACAAAATTTTATTTGAAATATCTATAAATTGTAAACTTA

CGTTATTTTTTATATGATATCAAGCATGTCAAGTATATGTGAAAAGTGACGCTATTGTTGCTTTAAATTATGTAAGTATTT

AGATGCTCCTCTTTGTAACCTAACCATAATTTAATGTCCAATTAAGAGAACAATTCAATGTTTTTGCATTCTCCAATTTTG

ATCATATCGTAGATGGCGTAATCATAATCTTTTCCATTTTTTATGCATTTTAAAATATATTAAAATATTAATAATTGAA AT DCF2

ATATGTAAAAAAAATAAACAATTTATCTTGTAAATTTATTTCAAATTAAATATAAATTTTTTATTTAATCTTAATACTTCT $-454$

TTTTTCTAATTTGATCTTAATAATTTTAAAATTTTAAATTGGATTGAAGACTGATTTATAAAGATTACATTATAATACAGT

DRIF

TTATCATTAAGAACAGAAAACTATATAACTTTATATAAAGTAGAGTCAACTTATTTCACATTTATCAAATTAATAAGAAAT

DCF2

GTGTATTTCTTGTTTCTATTTTCAAATAGAATAAAACTTTTAAATGTTTCTATATATTTATTATATATTTTATGCTAGATT

$-211$

AGAGTTGGCATTCACGTTGGAACATAGTTTGTGTCTGGAGTACTTGAATCGTTTCATGTTGCTTTTTCAAAATTTCTGATA DGTF

TTCCTTTTTGTCATTATTTTGTCATAAGATAAGAAAGTGAAAAAAGGAACAAAATAGTAAATAATCTTCGTAATATTGCAC

$\longleftrightarrow$ Transcription Start

ATACTTTATATAGATTTTGTAATTCACGTTTATAGGTAATTTAATCTATCACAAAATCAGTGTGGAACACGCAAATAAGAG

GAAGTATAATATACTACCGCATTTACGCACATACGTAGATATCTATGTTATTCGAACACATTAAGATCAATTAAAGTTATT GACGAAAAAAATTTTTAAATGTGATTACGTTGTAAGAAGA ATG

\section{$\longrightarrow$ Translation Start}

Fig. 5. The nucleotide sequence of the 5'-flanking region of AccS6K-p70. The transcription start site and the translation start site are marked with the arrows. The putative transcription factors are indicated and their binding sites are boxed. 
A

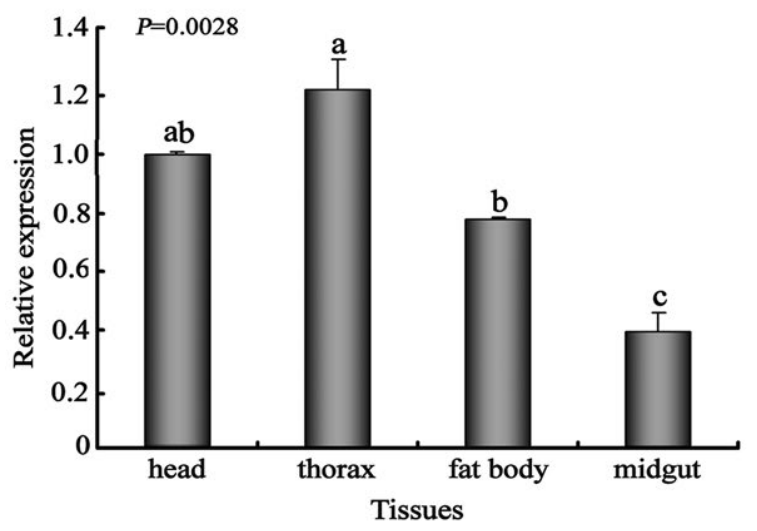

B

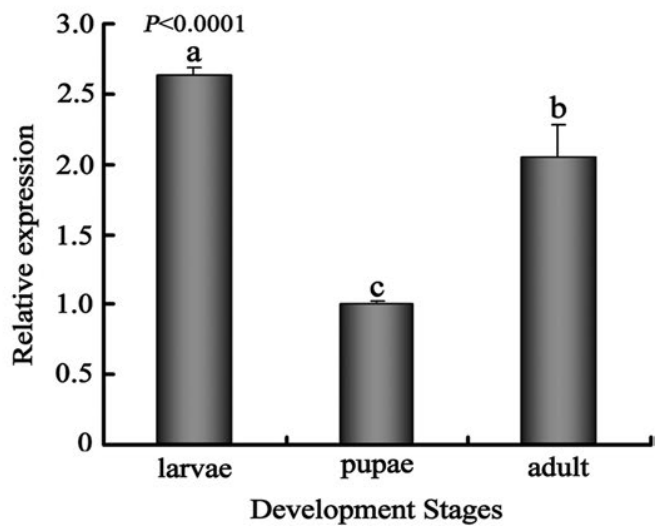

Fig. 6. Expression pattern of AccS6K-p70 in different tissues and developmental stages of A. c. cerana. A - AccS6K-p70 mRNA expression in different tissues measured by quantitative PCR. B - AccS6K-p70 mRNA expression in different developmental stages measured by quantitative PCR. Vertical bars represent the mean \pm SEM $(\mathrm{n}=3)$. Means labeled with different lowercase letters are highly significantly different $(P<0.01)$, as determined by Duncan's multiple range test using SAS version 9.1 software.

\section{Isolation and characterization of 5'-flanking region of AccS6K-p 70}

In order to further elucidate the molecular mechanism of transcriptional regulation of AccS6K-P7, the 1,425 bp 5'-flanking region of $A c c S 6 K-p 70$ was cloned (GenBank accession no. JF915528), and a series of transcription factor binding sites were predicted using the online web software MatInspector (Fig. 5). Three Drosophila Chorion Factor 2 (DCF2) binding sites, relevant to activation during myogenesis, were found in the 5 '-flanking region of $A c c S 6 K-p 70$ (Tanaka et al., 2008). Moreover, binding sites of other developmentally-relevant transcription factors, including Drosophila broad-complex for ecdysone steroid response (DBRC), Dead ringer factor (DRIF) and Drosophila T-cell factor (DTCF), were also found in the promoter region of $A c c S 6 K-p 70$ (Shandala et al., 1999; Consoulas et al., 2005; Chang et al., 2008) (Table 3). In addition, the binding site of Drosophila giant transcription factor (DGTF), as a typical transcription factor binding site, was found to be located up-stream of the transcription start site of $A c c S 6 K-p 70$. These transcription factor binding sites suggest that the AccS6K-p70 gene might be involved in multiple developmental processes in Chinese honeybees.

\section{Expression patterns of $A c c S 6 K-p 70$ in different tissues and developmental stages}

As several development relevant transcription factor binding sites were found in the 5'-flanking region of $A c c S 6 K-p 70$, to better elucidate the role $A c c S 6 K-p 70$ plays in $A$. c. cerana development, the expression level of $A c c S 6 K-p 70$ in different tissues and developmental stages was assayed. For different tissues, quantitative PCR analysis was performed using the RNA extracted from head, thorax, fat body, and midgut. The results indicated that the abundance of $A c c S 6 K-p 70$ transcript was relatively high in head and thorax compared to that in fat body and midgut (Fig. 6A). The highest AccS6K-p70 expression level was detected in thorax, which was 3.1-fold compared to the lowest expression level in midgut. Significant difference of $A c c S 6 K-p 70$ expression in transcriptional level was also found in different developmental stages (Fig. 6B). Following RNA extracted from larvae, pupae and adults, quantitative PCR analysis showed that expression levels of adults and larvae were 2.6-fold and 2.1-fold higher, respectively, compared to that of pupae. Together, these results show that expression of $A c c S 6 K-p 70$ at a transcriptional level was specific both in tissues and developmental stages, and that

TABLE. 3. The transcription binding sites of 5'-flanking region of AccS6K-p70.

\begin{tabular}{|c|c|c|}
\hline Transcription factor & Binding sites & Possible function \\
\hline $\begin{array}{l}\text { DCF2: Drosophila Chorion } \\
\text { Factor } 2\end{array}$ & 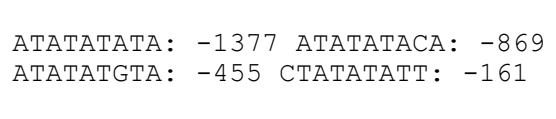 & $\begin{array}{l}\text { Zinc finger transcriptional regulator playing a } \\
\text { critical role in activation of myogenesis process } \\
\text { (Tanaka et al., 2008) }\end{array}$ \\
\hline $\begin{array}{l}\text { DBRC: Drosophila broad-complex } \\
\text { for ecdysone steroid response }\end{array}$ & GAATTTGATAAATAAAAGT: $\quad-1363$ & $\begin{array}{l}\text { Ecdysone steroid responsive transcription factor } \\
\text { essential for insect molting (Consoulas et al., 2005) }\end{array}$ \\
\hline DRIF: Dead ringer factor & $\begin{array}{l}\text { ATAATTAATTA: }-939 \text { ATAATTAAAAT: } \\
\text {-793 CAAATTAATAA: }-226\end{array}$ & $\begin{array}{l}\text { A member of ARID-box family essential for muscle } \\
\text { development in the embryo (Shandala et al., 1999) }\end{array}$ \\
\hline DTCF: Drosophila T-cell factor & AATTTTGATCATA: -541 & $\begin{array}{l}\text { Transcription factor regulating target gene in win- } \\
\text { gless signalling (Chang et al., 2008) }\end{array}$ \\
\hline $\begin{array}{l}\text { DGTF: Drosophila giant } \\
\text { transcription factor }\end{array}$ & СTTTTTGTCATTATT: $\quad-45$ & Typical transcription factor in Drosophila \\
\hline
\end{tabular}


A

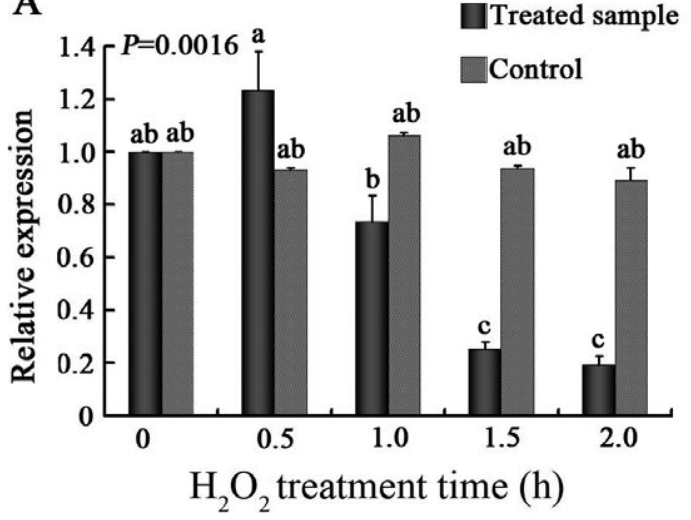

B

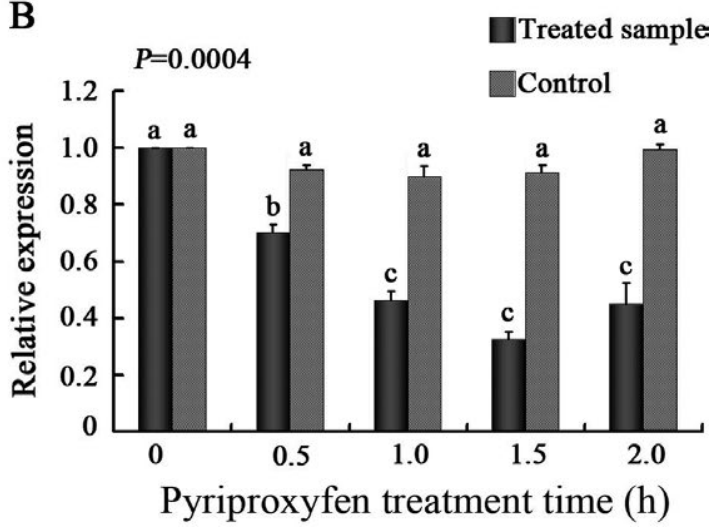

Fig. 7. Expression pattern of $A c c S 6 K-p 70$ in $A$. cerana cerana under oxidative stress and pesticide. A - AccS6K- 70 mRNA expression under $\mathrm{H}_{2} \mathrm{O}_{2}$ treatment measured by quantitative PCR. Vertical bars represented the mean $\pm \mathrm{SEM}(\mathrm{n}=3)$. B $-A c c S 6 K-p 70$ mRNA expression with treatment of pyriproxyfen measured by quantitative PCR. Means labeled with different lowercase letters are highly significantly different $(P<0.01)$, as determined by Duncan's multiple range test using SAS version 9.1 software.

$A c c S 6 K-p 70$ may play an important role/s in the developmental processes of the Chinese honeybee.

\section{Expression patterns of $A c c S 6 K-p 70$ in response to $\mathrm{H}_{2} \mathrm{O}_{2}$ and pesticide}

Nowadays, as outlined in the Introduction, $A$. $c$. cerana is faced with increasingly severe environmental stresses (Xu et al., 2009), which may exert effects on the life span of the insect and thereby directly affect the agricultural industry. S6K-p70 was reported to be involved in cell survival in response to oxidative stress induced apoptosis (Harada et al., 2001; Proud, 2004; Taga et al., 2011). Pyriproxyfen, a commonly used pesticide both in China and elsewhere (Schaefer \& Mulligan, 1991), acts by impairing insect development. To investigate the effects of pyriproxyfen and oxidative stress on the expression of AccS6K-p70, Chinese honeybees (adults) were treated with pyriproxyfen and $\mathrm{H}_{2} \mathrm{O}_{2}$, which was used to imitate oxidative stress, and the level of transcriptional expression of $A c c S 6 K-p 70$ assessed after exposing them to both these stress agents. The expression level was normalized to that of a control sample. Following $\mathrm{H}_{2} \mathrm{O}_{2}$ treatment, the transcriptional level expression of $A c c S 6 K-p 70$ was slightly up-regulated at $0.5 \mathrm{~h}$ post treatment and thereafter clearly decreased at $1 \mathrm{~h}, 1.5 \mathrm{~h}$, and $2 \mathrm{~h}$ post treatment (Fig. 7A). Exposure to $\mathrm{H}_{2} \mathrm{O}_{2}$ for two hours caused the lowest expression level of AccS6K-p70, which was onefifth of that in control sample. The expression of $A c c S 6 K-p 70$ decreased significantly after treating with pyriproxyfen and exposure to this compound for $1.5 \mathrm{~h}$ caused the lowest expression level of AccS6K-p70 of all (Fig. 7B). These results show that AccS6K-p70 undoubtedly has relevance to cell survival, and the functions of the gene/ gene products might well be influenced by both $\mathrm{H}_{2} \mathrm{O}_{2}$ and pyriproxyfen via down-regulation of AccS6K-p70 itself, as here demonstrated.

\section{DISCUSSION}

Previous studies have shown that S6K-p70 is involved in developmental processes and cell survival (Harada et al., 2001). The Chinese honeybee, A. c. cerana, being an important pollinator, is of great importance to the ecological environment as well as the agricultural industry. In this study, the gene $A c c S 6 K-p 70$ was isolated and characterized for the first time. Sequence and structure analysis of AccS6K-p70 showed that the conserved phosphorylation site found in the salient activation loop might be of importance for the catalytic activity of the protein, since this site was the phosphorylation site of PDK1 and related to the activity of another conserved phosphorylation site in the SKAIPS domain (Keshwani et al., 2011). Phylogenetic analysis indicates that compared to the S6K-p70 protein in Diptera and Lepidoptera, the S6K-p70 protein from Hymenoptera is clearly different. The difference was also found in the genomic structure of $S 6 K-p 70$. Thus, it is probable that the $S 6 K-p 70$ gene in $A$. c. cerana evolved specifically after divergence of insects orders.

Previous studies have demonstrated that S6K-p70 is involved in the protein synthesis signalling pathway, which plays an important role in developmental processes (Rintelen et al., 2001; Miron et al., 2003; Chiang \& Abraham, 2007). Here we show that AccS6K-p70 plays an important role in multiple developmental processes in A. c. cerana. First of all, expression amount of $A c c S 6 K-p 70$ varied in different developmental stages, which is consistent with other research results that show that the effect of S6K in D. melanogaster is age specific (Cho et al., 2010). In comparison to pupae, the expression level of $A c c S 6 K-p 70$ in the Chinese honeybee is relatively high in larvae and adults. Previous researches demonstrated that $S 6$ gene expression level was higher in larvae than in pupae and its phosphorylation is seemingly essential in the molting process in the tobacco hornworm moth, Manduca sexta (L.) (Song \& Gilbert, 1997; Consoulas et al., 2005). Further, the transcription factor binding site, essential in insect molting, has previously been found in the AccS6K-p70 5'-flanking region (Consoulas et al., 2005). Therefore, it was speculated in our work that AccS6K-p70 might play a critical role in the molting process of $A$. c. cerana, and relatively high expression of $A c c S 6 K-p 70$ in adults might be of relevance to adult 
tissue development. Tissue specific expression of AccS6K-p70 showed that the level of expression of $A c c S 6 K-p 70$ in head and thorax was significantly higher than that in other tissues. As the thorax is the centre of movement in honeybees, AccS6K-p70 might well be essential in flight muscle and organ development. This speculation is supported by muscle and organ development necessary transcription factor binding sites found in AccS6K-p70 5'-flanking region, as shown in several previous studies (Shandala et al., 1999; Chang et al., 2008; Tanaka et al., 2008). Moreover, it has been speculated that high expression of $A c c S 6 K-p 70$ in the head might be related to learning and memory formation, which is critical in honeybee foraging, since S6K-p70 seems to be involved in learning and memory formation via its participation in neuronal development (Pei \& Hugon, 2008; Swiech et al., 2008). All in all, AccS6K-p70 in A. $c$. cerana probably plays important roles in molting processes and in tissue development.

Honeybees are influenced by various environmental stresses during their life span. It was shown in our study that both $\mathrm{H}_{2} \mathrm{O}_{2}$ and pyriproxyfen could regulate AccS6K-p70 expression levels. Expression of AccS6K-p 70 slightly increased and then decreased significantly after exposure to $\mathrm{H}_{2} \mathrm{O}_{2}$. Previous studies revealed that S6K-p70 performed an anti-apoptotic function in response to oxidative stress, and the S6K-p70 mediated signalling pathway could be down-regulated by oxidative stress (Harada et al., 2001; Proud, 2004; Taga et al., 2011). It was thus inferred that AccS6K-p70 might be upregulated initially to defend oxidative stress and promote survival through inactivating the pro-apoptotic molecule BAD (Harada et al., 2001), whilst the AccS6K-p70dependent signalling pathway might be damaged by oxidative stress through inhibition of $A c c S 6 K-p 70$ expression (Proud, 2004; Taga et al., 2011). In addition to $\mathrm{H}_{2} \mathrm{O}_{2}$, the pesticide pyriproxyfen significantly down-regulates AccS6K-p70 expression, which in turn is probably essential in several critical developmental processes. As pyriproxyfen is considered to perform its function by influencing insect development, the insecticide may exert its effects on development by decreasing AccS6K-p70 expression.

In conclusion, in the present study, $A c c S 6 K-p 70$ was cloned and its expression profiles analyzed in $A$. $c$. cerana for the first time. The results strongly suggest that AccS6K-p70 plays an important role in the life history of A. c. cerana's by participating in molting, movement relevant muscle and organ development, learning and memory formation, and cell survival. Moreover, developmental processes are clearly influenced by oxidative stress and pyriproxyfen through down-regulation of $A c c S 6 K-p 70$ at the transcriptional level. In planned future studies, transgenic honeybees and immunohistochemical localization of AccS6K-p70 protein will be produced to further determine how it functions in development and survival of the Chinese honeybee.

ACKNOWLEDGEMENTS. This work was funded by the China Agriculture Research System (No. CARS-45), Agro-scientific
Research in the Public Interest (No. 200903006) and the National Natural Science Foundation (No. 31172275) in China. We thank H.D. Loxdale for his helpful comments on the manuscript.

\section{REFERENCES}

Arnold K., Bordoli L., Kopp J. \& Schwede T. 2006: The SWISS-MODEL Workspace: A web-based environment for protein structure homology modelling. - Bioinformatics 22: 195-201.

Azevedo S.V., Caranton O.A.M., Oliveira T.L. \& Hartfelder K. 2011: Differential expression of hypoxia pathway genes in honeybee (Apis mellifera L.) caste development. - J. Insect Physiol. 57: 38-45.

Chang M.V., Chang J.L., Gangopadhyay A., Shearer A. \& CADIGAN K. 2008: Activation of wingless targets requires bipartite recognition of DNA by TCF. - Curr. Biol. 18: 1877-1881.

Chiang G.G. \& Aвraham R.T. 2007: Targeting the mTOR signaling network in cancer. - Trends Mol. Med. 13: 433-422.

Cho I., Horn L., Felix T.M., Foster L., Gregory G., StarzGaiano M., Chambers M.M., Luca M.D. \& Leirs J. 2010: Age- and diet-specific effects of variation at S6 Kinase on life history, metabolic, and immune response traits in Drosophila melanogaster. - DNA Cell Biol. 29: 473-485.

Consoulas C., Levine R.B. \& Restifo L.L. 2005: The steroid hormone-regulated gene broad complex is required for dendritic growth of motorneurons during metamorphosis of Drosophila. - J. Compar. Neurol. 485: 321-337.

Distefano G., Boca M., Rowe I., Wodarczyk C., Ma L., Piontek K.B., Germino G.G., Pandolfi P.P. \& Boletta A. 2009: Polycystin-1 regulates extracellular signal-regulated kinase-dependent phosphorylation of tuberin to control cell size through mTOR and its downstream effectors S6K and 4EBP1. - Mol. Cell. Biol. 29: 2359-2371.

Ferrari S. \& Thomas G. 1994: S6 phosphorylation and the p70 $86 \mathrm{k} / \mathrm{p} 85^{\mathrm{s} 6 \mathrm{k}}$. - Critic. Rev. Biochem. Mol. Biol. 29: 385-413.

Foster D.A. 2004: Targeting mTOR-mediated survival signals in anticancer therapeutic strategies. - Expert Rev. Anti-Infect. Ther. 4: 691-701.

Geourjon C. \& Deleage G. 1995: SOPMA: significant improvements in protein secondary structure prediction by consensus prediction from multiple alignments. - Comput. Appl. Biosci. 11: 681-684.

GRIMALDI D. \& ENGEL E.S. 2005: Evolution of the Insects. Cambridge University Press, Cambridge, 772 pp.

Guex N. \& Peitsch M.C. 1997: SWISS-MODEL and the SwissPdbViewer: An environment for comparative protein modelling. - Electrophoresis 18: 2714-2723.

Harada H., Andersen J.S., Mann M., Terada N. \& Korsmeyer S.J. 2001: p70S6 kinase signals cell survival as well as growth, in activating the pro-apoptotic molecule BAD. Proc. Nat. Acad. Sci. U. S. A. 98: 9666-9670.

KAMAKURA M. 2011: Royalactin induces queen differentiation in honeybees. - Nature 26: 478-483.

Keshwani M.M., Daake S., Newton A.C., Harris T.K. \& TAYLOR S.S. 2011: Hydrophobic motif phosphorylation is not required for activation loop phosphorylation of p70 Ribosomal protein S6 kinase 1 (S6K1). - J. Biol. Chem. 286: 23552-23558.

Krab L.C., Goorden S.M.I. \& Elgersma Y. 2008: Oncogenes on my mind: ERK and MTOR signaling in cognitive diseases. - Cell 24: 498-510. 
Lane H.A., Fernandez A., Lamb N.J.C. \& Thomas G. 1993: p7 $70^{s 6 \mathrm{k}}$ function is essential for $\mathrm{G}_{1}$ progression. - Nature 363 $170-172$

LivaK K.J. \& SchmitTGEN T.D. 2001: Analysis of relative gene expression data using real-time quantitative PCR and the 2(-Delta Delta C(T)). - Methods 25: 402-408.

Miron M., Lasko P. \& Sonenberg N. 2003: Signaling from Akt to FRAP/TOR targets both 4E-BP and S6K in Drosophila melanogaster. - Mol. Cell. Biol. 23: 9117-9126.

Pei J. \& Hugon J. 2008: mTOR-dependent signalling in Alzheimer's disease. - J. Cell. Mol. Med. 12: 2525-2532.

Proud C.G. 2004: The multifaceted role of mTOR in cellular stress responses. - DNA Repair 3: 927-934.

Reinhard C., Thomas G. \& Kozma S.C. 1992: A single gene encodes two isoforms of the p70 S6 kinase: Activation upon mitogenic stimulation. - Proc. Nat. Acad. Sci. U. S. A. 89: 4052-4056.

Reinhard C., Fernanadez A., Lamb N.J.C. \& Thomas G. 1994: Nuclear localization of p85s6k: functional requirement for entry into $\mathrm{S}$ phase. - EMBO J. 13: 1557-1565.

Rintelen F., Stocker H., Thomas G. \& Hafen E. 2001: PDK1 regulates growth through Akt and $\mathrm{S} 6 \mathrm{~K}$ in Drosophila. Proc. Nat. Acad. Sci. U. S. A. 98: 15020-15025.

SChaefer C.H. \& Mulligan F.S. 1991: Potential for resistance to pyriproxyfen: A promising new mosquito larvicide. $-J$. Am. Mosq. Contr. Assoc. 7: 409-411.

Scheper M.A., Chaisuparat R., Nikitakis N.G. \& Sauk J.J. 2008: Expression and alterations of the PTEN/AKT/mTOR pathway in ameloblastomas. - Oral Dis. 14: 561-568.

Schwede T., Kopp J., Guex N. \& Peitsch M.C. 2003: SWISSMODEL: an automated protein homology-modeling server. - Nucl. Acids Res. 31: 3381-3385.

Shandala T., Kortschak R.D., Gregory S. \& Saint R. 1999: The Drosophila dead ringer gene is required for early embry- onic patterning through regulation of argos and buttonhead expression. - Development 126: 4341-4349.

Song Q. \& GiLbert L.I. 1997: Molecular cloning, developmental expression, and phosphorylation of ribosomal protein $\mathrm{S} 6$ in the endocrine gland responsible for insect molting. $-J$. Biol. Chem. 272: 4429-4435.

Stewart M.J., Berry C.A., Zilberman F., Thomas G. \& Kozma S.C. 1996: The Drosophila p70s6k homolog exhibits conserved regulatory elements and rapamycin sensitivity. Proc. Nat. Acad. Sci. U. S. A. 93: 10791-10796.

Swiech L., Perycz M., Malik A. \& Jaworski J. 2008: Role of mTOR in physiology and pathology of the nervous system. - Biochim. Biophys. Acta 1784: 116-132.

Taga M., Mouton-Liger F., Paquet C. \& Hugon J. 2011: Modulation of oxidative stress and tau phosphorylation by the mTOR activator phosphatidic acid in SH-SY5Y cells. FEBS Letters 585: 1801-1806.

Tanaka K.K., Bryantsev A.L. \& Cripps R.M. 2008: Myocyte enhancer factor 2 and chorion factor 2 collaborate in activation of the myogenic program in Drosophila. - Mol. Cell. Biol. 28: 1616-1629.

Watson K.L., Chou M.M., Blenis J., Gelbart W.M. \& Erikson R.L. 1996: A Drosophila gene structurally and functionally homologous to the mammalian $70-\mathrm{kDa}$ S6 kinase gene. Proc. Nat. Acad. Sci. U. S. A. 93: 13694-13698.

Weng Q.P., Kozlowski M., Belham C., Zhang A., Comb M.J. \& Avruch J. 1998: Regulation of the p70 S6 Kinase by phosphorylation in vivo. - J. Biol. Chem. 273: 16621-16629.

Xu P., Shi M. \& Chen X.X. 2009: Antimicrobial peptide evolution in the Asiatic honeybee Apis cerana. - PLoS One 4: e4239.

Yu F., Kang M., Meng F., Guo X. \& Xu B. 2011: Molecular cloning and characterization of a thioredoxin peroxidase gene from Apis cerana cerana. - Insect Mol. Biol. 20: 367-378.

Received May 28, 2012; revised and accepted July 9, 2012 